\title{
Unilateral Measles-Associated Retrobulbar Optic Neuritis without Encephalitis: A Case Report and Literature Review
}

\author{
Takehisa Hirayama $^{a}$ Ken Ikeda ${ }^{a}$ Takanobu Hidaka ${ }^{b}$ \\ Riya Nagata ${ }^{a}$ Yasuhiro Yoshii ${ }^{a}$ Kiyokazu Kawabe $^{\mathrm{a}}$ \\ Yasuo Iwasaki ${ }^{a}$
}

Departments of Neurology, ${ }^{a}$ Toho University Omori Medical Center, and ${ }^{\mathrm{b}}$ Makita

General Hospital, Tokyo, Japan

\section{Key Words}

Measles virus · Optic nerve MRI · Quadrantanopsia · Retrobulbar optic neuritis

\begin{abstract}
Optic neuritis $(\mathrm{ON})$ is a rare neurological complication of measles infection. Little is known about measles-associated retrobulbar ON. Here, we report a distinct patient with unilateral retrobulbar $\mathrm{ON}$ due to measles infection. A 26-year-old woman developed maculopapular rash and Koplik spots. On the following 3 days, she noticed blurred vision in the left eye. A Goldmann visual field test showed inferior nasal quadrantanopsia in the left eye. Visual acuity was 20/20 in OD and 20/100 in OS. Pupillary size was $2.0 \mathrm{~mm}$ in the right eye and $4.0 \mathrm{~mm}$ in the left eye. Light reflexes were slightly sluggish in the left eye. Ophthalmoscopy showed mild pallor of the left optic disc. Central critical flicker fusion frequency (CFF) was $40.7 \mathrm{~Hz}$ in the right eye and $10.1 \mathrm{~Hz}$ in the left eye (normal $\geq 29.0$ ). Visual evoked potentials showed that P100 latencies were delayed on the left side (133 ms). Brain and spinal cord MRI was normal. Orbital MRI displayed abnormal enhancement in the left optic nerve. Serum and cerebrospinal fluid IgG titers of anti-measles antibodies were increased. Left measles-associated ON was diagnosed. Methylprednisolone pulse therapy followed by oral administration of prednisolone ameliorated visual acuity, visual field and CFF. The neuroophthalmic profile of our patient indicated that measles infection triggered isolated retrobulbar ON, leading to unusual visual deficits. Thus, physicians should pay more attention to variable patterns of measles-associated ON.
\end{abstract}




\section{Introduction}

Measles virus, a neurotrophic virus, is known to cause various kinds of neurological complications $[1,2]$, with a frequency of 4 neurological insults per 1,000 cases of measles infection. Measles encephalitis or impaired consciousness was observed in 1 per 1,000 cases [1] and commonly in children or adults $>10$ years of age [1]. Acute optic neuritis $(\mathrm{ON})$ was described in patients with measles encephalitis [3,4], whereas isolated ON was found in patients without measles encephalomyelitis [4-8]. Based on lesion topography, measles-associated ON could be divided into anterior and retrobulbar types. Anterior ON or papillitis due to measles infection was reported previously in several patients without other neurological deficits [4-7]. Little is known about measles-associated retrobulbar ON $[2,3,8]$. Here, we report a distinct patient with unilateral measles-associated retrobulbar ON.

\section{Case Report}

A 26-year-old healthy woman developed fever and maculopapular rash expanding from the face to the trunk and the four limbs. Subsequently, Koplik spots were present and measles was diagnosed. Three days after the onset of rash, she noticed blurred vision in the left eye. One week later, she visited a neighboring hospital and quadrantanopsia was found in her left eye. She was admitted to our department. Physical examination was normal. A Goldmann visual field test revealed inferior nasal quadrantanopsia without central scotomas in her left eye. The visual field of her right eye was normal ( $\underline{\text { fig. 1) }}$. The corrected visual acuity was $20 / 20$ in OD and 20/100 in OS. Pupillary size was $2.0 \mathrm{~mm}$ in the right eye and $4.0 \mathrm{~mm}$ in the left eye. Light reflexes were slightly sluggish in her left eye. Ophthalmoscopy showed mild pallor of the left optic disc. Neurological examination was normal except for visual dysfunction. Routine laboratory tests, electrocardiogram and chest X-ray were normal. Serum IgG titers of anti-measles antibodies were increased to 1:94.8 in an enzyme immunoassay (normal $<1: 2.0$ ). Cerebrospinal fluid (CSF) examination disclosed a cell count of 1 mononuclear cell $/ \mathrm{mm}^{3}$, protein levels of $38 \mathrm{mg} / \mathrm{dl}$ and cytology of class II. Myelin basic protein and oligoclonal IgG bands were negative. CSF IgG titers of anti-measles antibodies were elevated to 1:0.64 (normal $<1: 0.20$ ). Serum anti-aquaporin 4 antibodies were not detected. In electrophysiological studies, sensory and auditory evoked potential tests were normal. An electroencephalogram was normal. Central critical flicker fusion frequency (CFF) showed $40.7 \mathrm{~Hz}$ in her right eye and $10.1 \mathrm{~Hz}$ in her left eye (normal $\geq 29.0$ ). P100 latencies of visual evoked potentials disclosed $90.6 \mathrm{~ms}$ on the right side and $133 \mathrm{~ms}$ on the left side. Brain and spinal cord MRI revealed no pathognomonic lesions. Orbital MRI displayed abnormal enhancement in the left optic nerve (fig. 2). Our patient had seropositive and CSF-positive anti-measles antibodies, neuroophthalmic findings and abnormal enhancement of the left optic disc. These findings supported the diagnosis of unilateral measles-associated retrobulbar ON. Methylprednisolone pulse therapy $(1,000$ $\mathrm{mg} /$ day for 3 days, i.v.) and subsequent administration of prednisolone ( $1 \mathrm{mg} / \mathrm{kg}$ per day, p.o.) were performed. Prednisolone was tapered off within 1 month. After steroid treatment, left quadrantanopsia was improved and left visual acuity also normalized to 20/20. CFF was increased to $36.4 \mathrm{~Hz}$ in her left eye.

\section{Discussion}

The neuroophthalmologic profile and MRI of our patient suggested unilateral measlesassociated retrobulbar $\mathrm{ON}$ without $\mathrm{CNS}$ involvement.

Measles virus can generate various types of neurological complications [1,2]. This neurotrophic virus is known to provoke acute ON together with CNS deficits or encephalitis $[3,8]$. Twelve patients with measles-induced acute $\mathrm{ON}$ were reviewed previously [4]. Of the 12 patients, 7 had no signs of CNS involvement [5, 6, 9-13]. The age 
at onset was 6-14 years [6, 9-13]. Previously published reports of 10 patients with isolated measles-associated $\mathrm{ON}$ are listed in table 1 . Bilateral visual deficits were found in 9 patients and unilateral disturbance in 1 patient [5]. Visual loss occurred commonly within the first weeks after rash. Two patients experienced visual disturbance several days before cutaneous symptoms $[5,10]$. Ophthalmoscopy was performed in 9 patients. Fundus findings exhibited edematous optic disc in 6 patients, pallor optic disc in 1 patient and normal results in 2 . Therefore, anterior $\mathrm{ON}$ or papillitis most often occurs in patients with measles-associated $\mathrm{ON}$. Occurrence of retrobulbar ON is extremely rare, with only 4 cases being reported previously $[2,3,8]$. In a Japanese article, 2 patients (a 4-year-old girl and a 18-year-old boy) developed retrobulbar $\mathrm{ON}$ after measles encephalitis [3]. In another study, a Japanese female patient with measles had retrobulbar ON, Guillain-Barré syndrome and asymptomatic brain MRI lesions [5]. Another case (a 25-year-old woman) had retrobulbar ON without CNS lesions after measles. Her visual acuity of both eyes was counting fingers at $2 \mathrm{~m}$ whereas optic discs were normal on ophthalmoscopy [8].

Several aspects of measles-associated $\mathrm{ON}$ are thought to mimic acute $\mathrm{ON}$ in patients with multiple sclerosis or neuromyelitis optica. A variety of visual field defects occur in optic neuropathies, including central, centrocecal, arcuate, altitudinal and nasal step field defects. The cardinal field defect of acute $\mathrm{ON}$ is a widespread depression of sensitivity and a central scotoma. However, other visual field changes such as bitemporal hemianopsia, a paracentral scotoma and altitudinal deficits may be observed in some ON patients. Noncentral scotoma or atypical defects in the visual field have been found in neuromyelitis optica patients [14]. A recent quantitative study of laser polarimetry was performed in 25 patients with a single episode of ON. Superior and inferior quadrant retinal nerve fiber layer thinning was correlated with corresponding regional visual field loss [15]. Our patient developed inferior nasal quadrantanopsia in the left eye. Visual evoked potentials and orbital MRI clarified the left optic nerve lesion. The possibility was suspected that damage to the inferior quadrant retinal nerve fibers could cause corresponding quadrantanopsia.

In conclusion, unilateral measles-associated retrobulbar $\mathrm{ON}$ was noted in a patient without CNS lesions. Thus, physicians should pay more attention to variable patterns of acute $\mathrm{ON}$ triggered by measles virus.

\section{Disclosure Statement}

All authors declare no conflict of interest. 


\begin{tabular}{c|l|l|l}
$\begin{array}{c}\text { Case Reports in } \\
\text { NeUlology }\end{array}$ & $\begin{array}{l}\text { Case Rep Neurol 2010;2:128-132 } \\
\text { DOI: 10.1159/000322143 }\end{array}$ & $\begin{array}{l}\text { Published online: } \\
\text { November 3, 2010 }\end{array}$ & $\begin{array}{l}\text { O 2010 S. Karger AG, Basel } \\
\text { ISSN 1662-680X } \\
\text { www.karger.com/crn }\end{array}$ \\
\hline
\end{tabular}

Table 1. Previous reports of isolated measles-associated ON

\begin{tabular}{|c|c|c|c|c|c|c|}
\hline First author & Year & $\begin{array}{l}\text { Patient } \\
\text { age }\end{array}$ & $\begin{array}{l}\text { Onset } \\
\text { after rash }\end{array}$ & Visual acuity & Optic disc & Visual recovery \\
\hline Shlossberg [9] & 1940 & 6 years & 5 days & no light perception in OU & edema in $\mathrm{OU}$ & $4 / 200$ in OD, $3 / 200$ in OS \\
\hline Wagener [10] & 1952 & 7 years & -6 days & $13 / 200$ in $\mathrm{OU}$ & edema in OU & $20 / 20$ in OU \\
\hline Bedrossian [11] & 1955 & 6 years & 6 days & light perception in OU & edema in OU & $20 / 30$ in OU \\
\hline Tyler [12] & 1957 & 8 years & 12 days & $1 / 500$ in $\mathrm{OU}$ & pallor in OU & normal in $\mathrm{OU}$ \\
\hline Kennedy [13] & 1960 & 6 years & 2 days & hand movements in $\mathrm{OU}$ & edema in $\mathrm{OU}$ & $20 / 20$ in $\mathrm{OU}$ \\
\hline Srivastava [5] & 1963 & 8 years & -1 day & hand movements in OS & edema in OS & $20 / 30$ in OS \\
\hline Walsh [6] & 1969 & 14 years & 5 days & blindness in OU & & $\begin{array}{l}\text { 20/200 in OD, } \\
\text { hand movements in OS }\end{array}$ \\
\hline Totan $[8]$ & 1999 & 25 years & 11 days & counting fingers in $\mathrm{OU}$ & normal $^{1}$ & $20 / 20$ in OD, $20 / 25$ in OS \\
\hline Azuma [7] & 2002 & 31 years & 6 days & counting fingers in $\mathrm{OU}$ & edema in OU & $20 / 20$ in OU \\
\hline Tomiyasu [2] & 2009 & 28 years & 8 days & $2 / 200$ in OD, $6 / 200$ in OS & normal $^{1}$ & $20 / 40$ in OD, $20 / 16$ in OS \\
\hline Present case & 2010 & 26 years & 3 days & $20 / 20$ in OD, $20 / 100$ in OS & pallor in $\mathrm{OS}^{1}$ & $20 / 20$ in OS \\
\hline
\end{tabular}

${ }^{1}$ Retrobulbar ON.
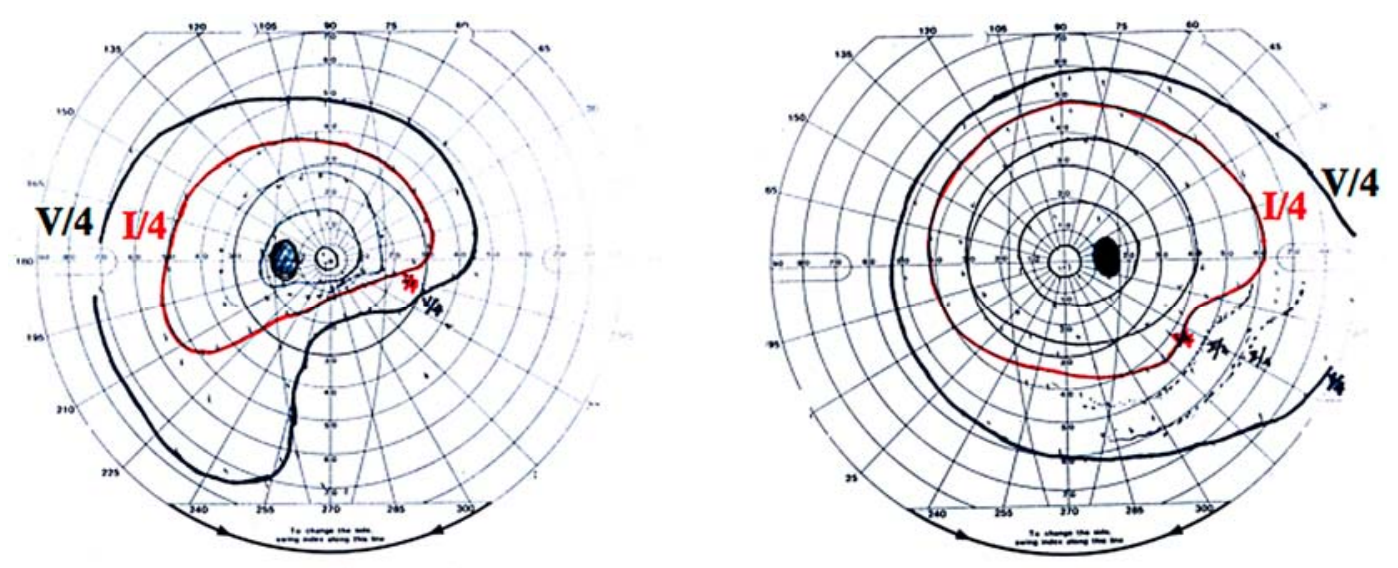

Fig. 1. Goldmann visual field test shows inferior nasal quadrantanopsia in the left eye. 


\begin{tabular}{c|l|l|l} 
Case Reports in & $\begin{array}{l}\text { Case Rep Neurol 2010;2:128-132 } \\
\text { DOI: } 10.1159 / 000322143\end{array}$ & $\begin{array}{l}\text { Published online: } \\
\text { November 3, 2010 }\end{array}$ & $\begin{array}{l}\odot \text { ISSN 1662-680X } \\
\text { www.karger.com/crn }\end{array}$ \\
\hline
\end{tabular}

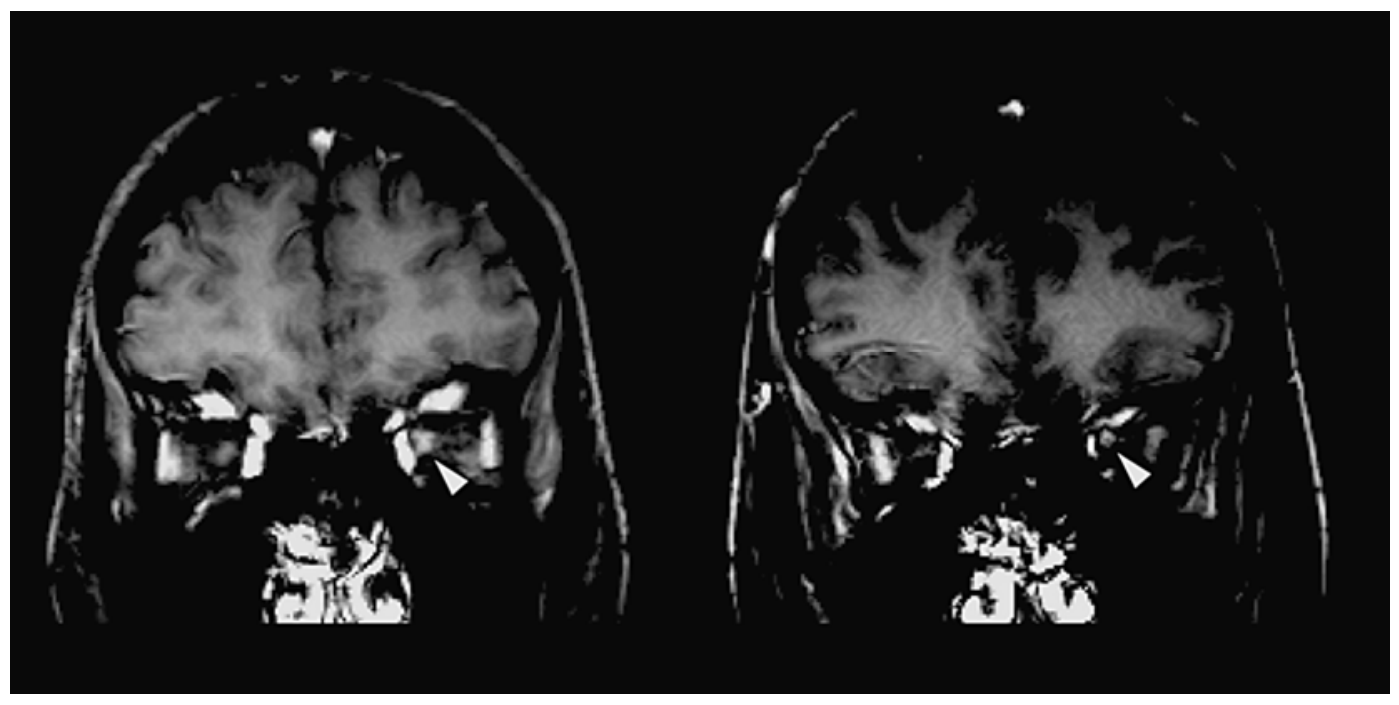

Fig. 2. Orbital MRI shows abnormal enhancement in the left optic nerve (arrowhead).

\section{References}

1 Miller DL: Frequency of complications of measles, 1963. Report on a National Inquiry by the Public Health Laboratory Service in Collaboration with the Society of Medical Officers of Health. Br Med J 1964;ii:75-78.

-2 Tomiyasu K, Ishiyama M, Kato K, Komura M, Ohnuma E, Inamasu J, Takahashi T: Bilateral retrobulbar optic neuritis, Guillain-Barré syndrome and asymptomatic central white matter lesions following adult measles infection. Intern Med 2009;48:377-381.

3 Inokuchi N, Nishikawa N, Fujikado T: Optic neuritis and measles infection. Nippon Rinsho 1997;56:861-864.

-4 Selbst RG, Selhorst JB, Harbison JW, Myer EC: Parainfectious optic neuritis. Report and review following varicella. Arch Neurol 1983;40:347-350.

5 Srivastava SP, Nema HV: Optic neuritis in measles. Br J Ophthalmol 1963;47:180-181.

6 Walsh FB, Hoyt WF: Clinical Neuro-Ophthalmology. Baltimore, Williams \& Wilkins, 1969, pp 1338-1375.

7 Azuma M, Morimura Y, Kawahara S, Okada AA: Bilateral anterior optic neuritis in adult measles infection without encephalomyelitis. Am J Ophthalmol 2002;134:768-769.

-8 Totan Y, Cekiç O: Bilateral retrobulbar neuritis following measles in an adult. Eye 1999;13:383-384.

9 Shlossberg FR, Prizer M: Retinal changes with marked impairment of vision in measles: report of a case. Am J Ophthalmol 1940;23:998-1000.

10 Wagener HP: Edema of the optic discs in cases of encephalitis. Am J Med Sci 1952;223:205-216.

11 Bedrossian RH: Neuroretinitis following measles. J Pediatr 1955;46:329-331.

12 Tyler HR: Neurological complication of rubeola (measles). Medicine 1957;36:147-167.

13 Kennedy C, Carroll FD: Optic neuritis in measles. Trans Am Acad Ophthalmol Otolaryngol 1960;64:700-712.

14 Nakajima H, Hosokawa T, Sugino M, Kimura F, Sugasawa J, Hanafusa T, Takahashi T: Visual field defects of optic neuritis in neuromyelitis optica compared with multiple sclerosis. BMC Neurol 2010;10:45.

15 Trip SA, Schlottmann PG, Jones SJ, Kallis C, Altmann DR, Garway-Heath DF, Thompson AJ, Plant GT, Miller DH: Scanning laser polarimetry quantification of retinal nerve fiber layer thinning following optic neuritis. J Neuroophthalmol 2010;30:235-242. 